\title{
Feeding Ecology and Reproductive Biology of Some Economically Important Fish Species in the Tono Reservoir, Ghana
}

\author{
Daniel Nsoh Akongyuure \\ Department of Fisheries and Aquatic Resources Management, Faculty of Natural Resources and \\ Environment, University for Development Studies, Tamale, Ghana
}

akongyuure2012@gmail.com

\section{Keywords: Food Habit, Gonad, Gut Content, Phytoplankton, Reservoir, Tono, Zooplankton}

\begin{abstract}
The study of feeding ecology and reproductive biology ensures that the right management measures are applied for best output of fish stocks. Selection of good fish species for culture is also made possible through feeding and reproductive studies. Ghana over-relies on the culture of Nile tilapia and African catfish because there is no reliable scientific information on potential fish species that can be included for fish farming. The current study sought to investigate food habits and reproductive characteristics of economically important fish species in the Tono Reservoir of Northern Ghana. Monthly sampling was carried out from January, 2015 to December, 2016 (24 months). Specimens were obtained using cast net and gillnets of varying mesh sizes. Specimens were immediately transported to the laboratory in a chilled iced chest of temperature $4{ }^{\circ} \mathrm{C}$ for morphometric measurements and microscopic analysis of gut content and gonads. Thirty-three (33) individual food items were identified from all the fish species. Phytoplankton was the most important diet (Index of Relative Importance, IRI $=1923)$ whereas zooplankton was the least important diet (IRI = 35) out of the five major categories of food items identified from all the fish species. The major peaks of gonadosomatic index (GSI) of females were noted in February - March and June - July. Over $80 \%$ variation of fecundity was explained by the predictors (standard length, fish weight and gonad weight) for Clarias gariepinus and Auchenoglanis occidentalis. All the fish species were classified as omnivores and they spawned more than once in a year making all of them good candidates for aquaculture. Management measures should focus on regulating agricultural activities close to the reservoir and fishing activities in the reservoir for sustainable fish production and exploitation.
\end{abstract}

\section{Introduction}

Scientific knowledge and understanding of key population characteristics such as feeding and reproduction of fish are very necessary in the assessment and formulation of prudent management policies for fish stocks $[1,2]$. Similarly, complete information of feeding and reproduction of fish populations is vital for increased fish productions in capture fisheries and in aquaculture [3]. The accurate estimation of these parameters is crucial in any dependable fish stock assessment. In recent times where most capture fisheries are suffering from over-exploitation [4] trophic levels and mandatory release of egg-bearing females of some species among others are imperative in outlining different sustainable management measures of any fishery [5]. The life history of fishes is well understood by studying fecundity [6] and food habits [7]. Food habits are especially important because fish growth depends on the quantity and quality of food that is eaten. Food habits are described by identifying the species of food in the contents of the alimentary canal and their weight. The availability of data based on feeding ecology and reproductive biology could lead to a better understanding of differences in food habits and reproductive output of fish which would enhance the ability to estimate recruitment [8].

In Ghana, little is known about food ecology and reproductive biology of many freshwater fish species except few studies carried out by [9-12]. Though these previous studies have established basic information about selected freshwater fish species, they have not been able to explain the index of relative importance (IRI) of food items consumed by fish and have not indicated a regression model between fecundity and morphometric measurements like length and weight for clearer understanding 
of trophic levels and optimal foraging behavior [13] as well as key factors that affect fecundity of fish species. Results of the current study will give direction for fisheries management policies as well as render informed decision on the selection of new indigenous fish species for aquaculture. The main objective of this study was to investigate food habits and reproductive characteristics of economically important fish species in the Tono Reservoir of Northern Ghana.

To better understand factors influencing the food habits of the fish species, the following hypotheses were made. It was predicted that food items consumed by fish species will not vary with seasons. Furthermore, it was predicted that economically important fish species consumed different food items. Variables affecting fecundity of economically important fish species were also explored. It was predicted that the sex ratios of economically important fish species was the same. Additionally, factors such as standard length, fish weight and gonad weight of female specimens were predicted to influence fecundity.

\section{Materials and Methods}

\section{Study area}

The study was conducted in the Tono Reservoir situated on latitude $10^{\circ} 52^{\prime} \mathrm{N}$ and longitude $1^{\circ} 08^{\prime} \mathrm{W}$ (Figure 1). The construction of the reservoir began in 1975 and completed by 1985 mainly for irrigation and cattle watering purposes. The irrigation reservoir is the largest in Ghana [14] with storage capacity of $93000000 \mathrm{~m}^{3}$ [15], current total surface area of $12.5 \mathrm{~km}^{2}$ and an average depth of $7.7 \mathrm{~m}$ [16]. The area experiences 4 to 5 months short unimodal rainfall pattern and 7 to 8 months of the long dry season. The average annual rainfall is about $950 \mathrm{~mm}$ and that of temperature is $29{ }^{\circ} \mathrm{C}[17]$.

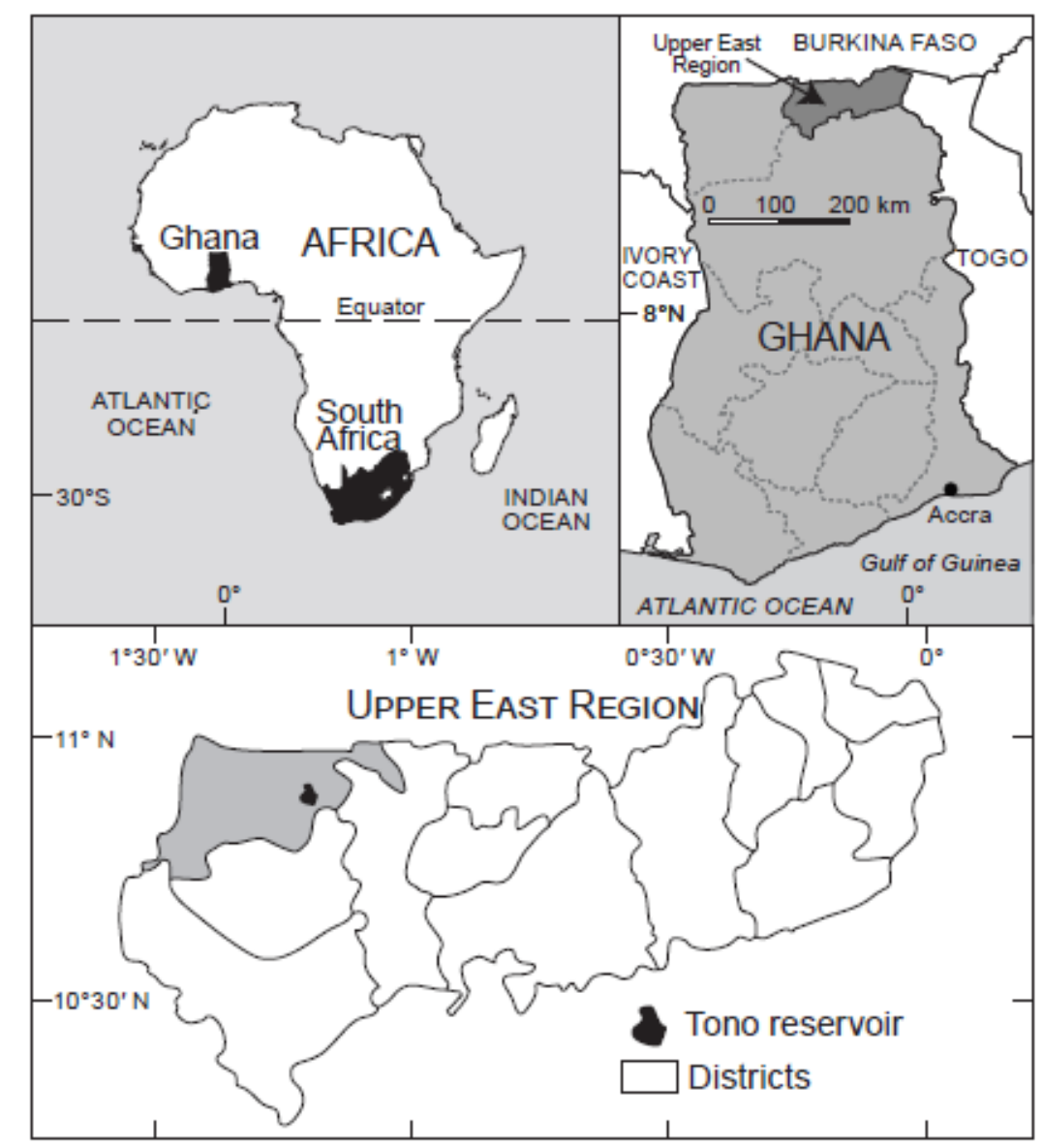

Figure 1. A map showing Tono Reservoir in the Upper East Region of Ghana. Source: [16] 


\section{Data Collection}

Monthly fish samples were obtained using cast nets $(2.5 \mathrm{~cm}$ mesh size $)$ and gillnets $(1.0-$ $7.5 \mathrm{~cm}$ ) for 24 months (January, 2015 - December, 2016). The fish were kept chilled in an ice chest immediately after capture and sent to the laboratory. At the laboratory, morphometric parameters (weight to the nearest $1.0 \mathrm{~g}$ and standard length to the nearest $0.1 \mathrm{~cm}$ ) of specimen were measured and recorded. Fish were dissected and the digestive system removed and preserved in $4 \%$ formalin. In order to examine the food item, the stomach was then taken out by cutting the alimentary tract between the end of oesophagus and the pylorus. The content was emptied into petri dishes. The weight of the stomach plus content and weight of content only from each individual specimen were taken using a digital scale to the nearest $0.0001 \mathrm{~g}$. Stomach content was first sorted by eye for larger food substances and secondly dispersed with small amount of distilled water; sub-samples were taken from the stock and observed and identified under a Celestron Digital LCD microscope at varying magnifications up to $\mathrm{x} 40$. Food items were identified up to the genus level wherever possible using identification keys by [18] for zooplankton and [19] for phytoplankton.

The sex of each specimen was identified firstly by visual examination and later confirmed after dissection and examination of the gonads. The gonads were removed from the other visceral organs and weighed to the nearest $0.0001 \mathrm{~g}$ using electronic balance. Maturity stage was graded visually based on a five-point scale [20] and tabulated (Table 1). A blend of external features and eye examination of split open body cavity of specimen was carried out to identify sex of fish. Tubular, pink and granular sex organs were considered as ovaries while the organs with flat, white and wavelike ventral edges outline were considered as testes. The testes also had a more flattened knife-edged shape than the ovaries. The gonads were removed from the other visceral organs and weighed to the nearest $0.0001 \mathrm{~g}$ using electronic balance. Ovaries of stages II to IV were preserved in Gilson's and left for at least 24 hours for the eggs to be liberated from ovarian tissues after which the eggs were washed with $70 \%$ ethanol [21].

\section{Data analysis}

Analysis of the data on gut contents was carried out using frequency of occurrence and numerical composition methods $[22,23]$. Stomach contents were examined and the individual food organisms sorted and identified. The number of stomachs in which each item occurred was recorded and expressed as a percentage of the total number of stomachs examined as follows [22, 23]:

$$
\text { Frequency of Occurrence }(F)=\frac{\text { Total no.of stomachs with particular food item }}{\text { Total no.of stomachs with food }} \times 100 \text {. }
$$

The total number of a particular food item was recorded and expressed as a percentage of total number of all food items during the study $[22,23]$

$$
\text { Numerical Method }(\mathrm{N})=\frac{\text { Total no.of particular food item }}{\text { Total no.of all food items }} \times 100 .
$$

The measures of frequency of occurrence $(\mathrm{F})$ and number of food items $(\mathrm{N})$ recorded in this study were integrated into an 'index of relative importance' (IRI) to determine the principal food item of the major fish species as:

$$
\mathrm{IRI}=\mathrm{F} \times \mathrm{N}[24]
$$

Mann-Whitney U test was performed to detect seasonal variation in food items consumed by the five fish species. Post-hoc analysis was done using Mann-Whitney U pairwise to identify differences in food items consumed by the fish species at $\alpha=0.05$ significance level using Paleontological Statistics version 3.11 (PAST).

Fecundity expressed as the number of eggs laid in a single season by the species was estimated using Gravimetric method [25]. 
Table 1. Description of gonad maturity stages of fish

\begin{tabular}{|c|c|c|}
\hline Stage & State & Description \\
\hline $\mathbf{0}$ & Virgin & $\begin{array}{l}\text { Very small gonads close under the vertebral column; testes } \\
\text { and ovaries colourless; eggs invisible to naked eye. }\end{array}$ \\
\hline I & $\begin{array}{l}\text { Maturing } \\
\text { virgin }\end{array}$ & $\begin{array}{c}\text { Testes and ovaries translucent; small eggs can be seen with } \\
\text { the aid of magnifying glass. }\end{array}$ \\
\hline II & Developing & $\begin{array}{l}\text { Ovaries reddish; eggs visible to eye. Testes appear as tiny } \\
\text { processes or strands }\end{array}$ \\
\hline III & Developed & $\begin{array}{c}\text { Ovaries orange-reddish. Eggs clearly discernible. Ovaries } \\
\text { occupy about two thirds of central cavity. Whitish milt } \\
\text { appears under slight pressure. }\end{array}$ \\
\hline IV & Gravid & $\begin{array}{l}\text { Ovaries filling ventral cavity, eggs completely round and } \\
\text { released from ovary with little pressure on abdomen. Testes } \\
\text { conspicuously bulky and whitish with milt flowing when } \\
\text { punctured. }\end{array}$ \\
\hline $\mathbf{V}$ & Spent & $\begin{array}{l}\text { Not yet fully empty. No opaque eggs left in ovaries; ovaries } \\
\text { large but flabby. Testes flabby and with remains of milt. }\end{array}$ \\
\hline
\end{tabular}

Source: Adopted from [20]

The sex ratio was determined using the proportion of the number of males to that of the females that were sampled monthly. It was calculated as follows:

$$
\text { Sex ratio }(\mathrm{SR})=\frac{\text { Number of males }}{\text { Number of females }}
$$

Chi-square test was used to determine if a population contains equal proportions of males and females at $\alpha=0.05$ significance level.

The gonadosomatic index (GSI) was estimated as the ratio of gonad mass to total body mass (a high value indicates a large investment in reproduction). The seasonal variation in the GSI was used to define the peak spawning periods, respectively. The GSI was calculated [26]:

$$
\text { SI }=\frac{\text { Gonad weight }(\mathrm{g})}{\text { Fish weight }(\mathrm{g})} \times 100 \text {. }
$$

The relationship between fecundity and standard length, weight of fish, and gonad weight were determined using multiple linear regression analysis at $\alpha=0.05$ significance level.

\section{Results}

\section{Food and feeding habits}

Table 2 shows the list of food items found in the stomach of the five commercially important fish species namely Auchenoglanis occidentalis, Clarias gariepinus, Oreochromis niloticus, Sarotherodon galilaeus and Coptodon zillii. The relative contributions of the food items are expressed by frequency of occurrence, numerical method and index of relative importance (IRI). A total of 714 randomly selected specimens were examined with standard length ranging from $9.8-15.0 \mathrm{~cm}$ for $C$. zillii to $21.2-33.0 \mathrm{~cm}$ for $C$. gariepinus and weight ranging from $36.0-155.0 \mathrm{~g}$ to $101.0-$ $256.7 \mathrm{~g}$ respectively. Thirty-three (33) major food items classified under phytoplankton, zooplankton, macrophyte, animal derivative and sand/detritus constituted the diet of the five fish species. Phytoplankton was the most important diet (IRI $=1923)$ with the highest frequency of occurrence whereas zooplankton was the least important (IRI $=35)$ with the lowest frequency of occurrence.

Table 3 presents the seasonal variation and correlation of food items found in the fish stomachs. There was no significant difference $(p>0.05)$ in food items found in the stomachs during dry and wet seasons for all the fish species except $S$. galilaeus. Correlation analysis showed that there was significant difference $(p<0.05)$ between food items found in the cichlids and $C$. gariepinus as well as $A$. occidentalis (Table 3 ). 
Table 2. Checklist and relative contribution of food items found in the stomachs of five major fish species of the Tono Reservoir, Ghana for 2015 - 2016

\begin{tabular}{|c|c|c|c|c|c|c|c|c|}
\hline Food item & \multicolumn{5}{|c|}{ Fish species } & $\begin{array}{c}\text { Freq. of } \\
\text { occur. (\%) }\end{array}$ & $\begin{array}{c}\text { Number } \\
(\%)\end{array}$ & IRI \\
\hline PHYTOPLANKTON & & & & & & & & \\
\hline Bacillariophyta (Diatoms) & & & & & & 25.0 & 10.1 & 253 \\
\hline Synedra sp. & - & - & iii & iv & $\mathrm{v}$ & & & \\
\hline Gyrosigma sp & & & iii & iv & $\mathrm{v}$ & & & \\
\hline Cyclotella $s p$ & & Ii & - & - & $\mathrm{v}$ & & & \\
\hline Chlorophyta (Green algae) & & & & & & 23.1 & 8.7 & 201 \\
\hline Carteria sp. & - & - & - & iv & $\mathrm{v}$ & & & \\
\hline Coelastrum $\mathrm{sp}$ & - & - & iii & iv & $\mathrm{v}$ & & & \\
\hline Volvox $\mathrm{sp}$ & $\mathrm{i}$ & - & - & - & $\mathrm{v}$ & & & \\
\hline Ankistrodesmus sp & - & - & - & iv & - & & & \\
\hline Pediastrum $\mathrm{sp}$ & - & - & - & iv & - & & & \\
\hline Stigeoclonium sp & - & Ii & iii & - & - & & & \\
\hline Scenedesmus sp & - & - & iii & - & - & & & \\
\hline Cosmarium sp & - & - & - & iv & - & & & \\
\hline Schroederia sp & - & - & - & iv & - & & & \\
\hline Staurastrum $\mathrm{sp}$ & _- & - & iii & iv & - & & & \\
\hline Cyanophyta (Blue-green algae) & & & & & & 40.4 & 26.0 & 1050 \\
\hline Anabaena sp. & $\mathrm{i}$ & - & iii & iv & $\mathrm{v}$ & & & \\
\hline Microcystis sp. & $\mathrm{i}$ & Ii & iii & iv & $\mathrm{v}$ & & & \\
\hline Pseudanabaena sp. & - & - & iii & iv & $\mathrm{v}$ & & & \\
\hline Lyngbya sp. & - & - & iii & - & - & & & \\
\hline Phormidium sp. & - & - & - & iv & $\mathrm{v}$ & & & \\
\hline Chrysophyta & & & & & & 3.8 & 1.4 & 5 \\
\hline Surirella sp. & - & - & iii & iv & - & & & \\
\hline Euglenophyta (Euglenoids) & & & & & & 1.92 & 0.7 & 1 \\
\hline Phacus sp. & - & - & iii & - & $\mathrm{v}$ & & & \\
\hline Charophyta & & & & & & 0.96 & 0.7 & 1 \\
\hline Closterium sp. & $\mathrm{i}$ & ii & - & - & - & & & \\
\hline Heterokontophyta & & & & & & 32.69 & 12.6 & 412 \\
\hline Tribonema sp & $\mathrm{i}$ & - & iii & iv & $\mathrm{v}$ & & & \\
\hline ZOOPLANKTON & & & & & & & & \\
\hline Arthropoda (Phylum) & & & & & & 9.62 & 3.6 & 35 \\
\hline Polyphemus sp. & $\mathrm{i}$ & - & - & - & - & & & \\
\hline Cypridopsis sp. & $\mathrm{i}$ & - & - & iv & $\mathrm{v}$ & & & \\
\hline Chironomus sp. & - & ii & - & - & - & & & \\
\hline Canthocamptus sp. & - & - & - & - & $\mathrm{v}$ & & & \\
\hline Sida $\mathrm{sp}$ & - & - & iii & - & - & & & \\
\hline Rotifera & & & & & & 0.96 & 0.4 & $*$ \\
\hline Brachionus sp. & - & - & iii & - & - & & & \\
\hline MACROPHYTES & & & & & & 10.58 & 5.1 & 54 \\
\hline Plant parts & $\mathrm{i}$ & ii & - & iv & - & & & \\
\hline ANIMAL DERIVATIVES & & & & & & 30.77 & 12.3 & 378 \\
\hline Worm & $\mathrm{i}$ & ii & iii & - & $\mathrm{v}$ & & & \\
\hline Insect remains & $\mathrm{i}$ & ii & iii & iv & - & & & \\
\hline Fish remains & $\mathrm{i}$ & ii & - & iv & $\mathrm{v}$ & & & \\
\hline SAND/DETRITUS & $\mathrm{i}$ & ii & iii & iv & $\mathrm{v}$ & 23.08 & 13.0 & 300 \\
\hline UNIDENTIFIED & $\mathrm{i}$ & ii & iii & iv & $\mathrm{v}$ & $\begin{array}{c}11.54 \\
\mathrm{n}_{\text {total }}=104\end{array}$ & $\begin{array}{c}5.4 \\
\mathrm{~N}_{\text {total }}=277\end{array}$ & 62 \\
\hline
\end{tabular}

*Indicates IRI value $<0.1$

$\mathrm{n}$ is total number of stomachs with food

$\mathrm{N}$ is total number of food items identified

- indicates absence of food item in fish stomach

$\mathrm{i}=$ A. occidentalis $; \mathrm{ii}=C$. gariepinus $;$ iii $=O$. niloticus $;$ iv $=S$. galilaeus $; \mathrm{v}=C$. zillii 
Table 3. Seasonal variation and correlation of food items consumed by five major fish species of Tono Reservoir, Ghana from 2015 - 2016

\begin{tabular}{|c|c|c|c|c|c|}
\hline \multicolumn{6}{|c|}{ A. Seasonal variation } \\
\hline & $N$ & Mean rank & $\begin{array}{c}\text { Mann-Withn. } \\
U\end{array}$ & $Z$-value & $P$-value \\
\hline \multicolumn{6}{|l|}{ S. galilaeus } \\
\hline Dry & 12 & 8.732 & 117 & -2.950 & $0.003 *$ \\
\hline Wet & 44 & 19.768 & & & \\
\hline \multicolumn{6}{|c|}{ O. niloticus } \\
\hline Dry & 34 & 17.054 & 513.5 & -0.172 & 0.863 \\
\hline Wet & 31 & 15.946 & & & \\
\hline \multicolumn{6}{|c|}{ C. zillii } \\
\hline Dry & 29 & 14.745 & 317 & -0.029 & 0.977 \\
\hline Wet & 22 & 11.255 & & & \\
\hline \multicolumn{6}{|c|}{ C. gariepinus } \\
\hline Dry & 11 & 4.704 & 61.0 & -1.358 & 0.174 \\
\hline Wet & 16 & 9.296 & & & \\
\hline \multicolumn{6}{|c|}{ A. occidentalis } \\
\hline Dry & 30 & 16.218 & 102.5 & -1.074 & 0.282 \\
\hline Wet & 9 & 3.782 & & & \\
\hline \multicolumn{6}{|c|}{ B. Correlation of food items } \\
\hline & A. occidentalis & C. gariepinus & O. niloticus & S. galilaeus & C. zillii \\
\hline A. occidentalis & & 0.470 & $0.000 *$ & $0.000^{*}$ & $0.003 *$ \\
\hline C. gariepinus & 0.470 & & $0.000 *$ & $0.000 *$ & $0.001 *$ \\
\hline O. niloticus & $0.001 *$ & $0.000 *$ & & 0.141 & 0.967 \\
\hline S. galilaeus & $0.000 *$ & $0.000 *$ & 0.141 & & 0.200 \\
\hline C. zillii & $0.003 *$ & $0.001 *$ & 0.967 & 0.200 & \\
\hline
\end{tabular}

* Indicates $p$-values that are significant $(p<0.05)$

\section{Reproductive Characteristics}

The overall sex ratio (male: female) of 714 specimens was 1.2:1.0. A chi-square test indicated significant difference $(p<0.05)$ for the sex ratios of $A$. occidentalis and $C$. gariepinus but showed no significant difference $(p>0.05)$ for $O$. niloticus, $S$. galilaeus and $C$. zillii from the expected 1:1 ratio (Table 4). The highest mean GSI was recorded in $S$. galilaeus and lowest in C. gariepinus (Table 4). The major peaks of GSI of females were noted in February - March and June - July (Fig. 2). 
Table 4. Reproductive characteristics of five major fish species of the Tono Reservoir, Ghana in 2015 and 2016

\begin{tabular}{cccccc}
\hline & S. galilaeus & O. niloticus & C. zillii & C. gariepinus & A. occidentalis \\
\hline Male: Female & $1.3: 1.0$ & $1.0: 1.0$ & $1.0: 1.1$ & $3.1: 1.0$ & $2.8: 1.0$ \\
$N$ & 2 & 2 & 2 & 2 & 2 \\
$D F$ & 1 & 1 & 1 & 1 & 1 \\
$\chi^{2}$ & 1.203 & 0.023 & 0.343 & 12.086 & 15.899 \\
$p$-value & 0.273 & 0.879 & 0.558 & $0.000^{*}$ & $0.000^{*}$ \\
Fecundity \pm S.D & $511 \pm$ & $472 \pm 145.7$ & $444 \pm$ & $1375 \pm 691.7$ & $692 \pm 287.6$ \\
GSI \pm S.D. & 161.7 & & 163.6 & & \\
SL range (cm) & $8.4-14.5$ & $9.8-15.0$ & $9.8-15.0$ & $21.2-33.0$ & $16.0-31.0$ \\
Weight range (g) & $28.0-$ & $42.0-119.0$ & $36.0-$ & $101.0-256.7$ & $80.0-835.0$ \\
& 129.0 & & 155.0 & & \\
\end{tabular}

*Indicates significantly different at $p<0.05$

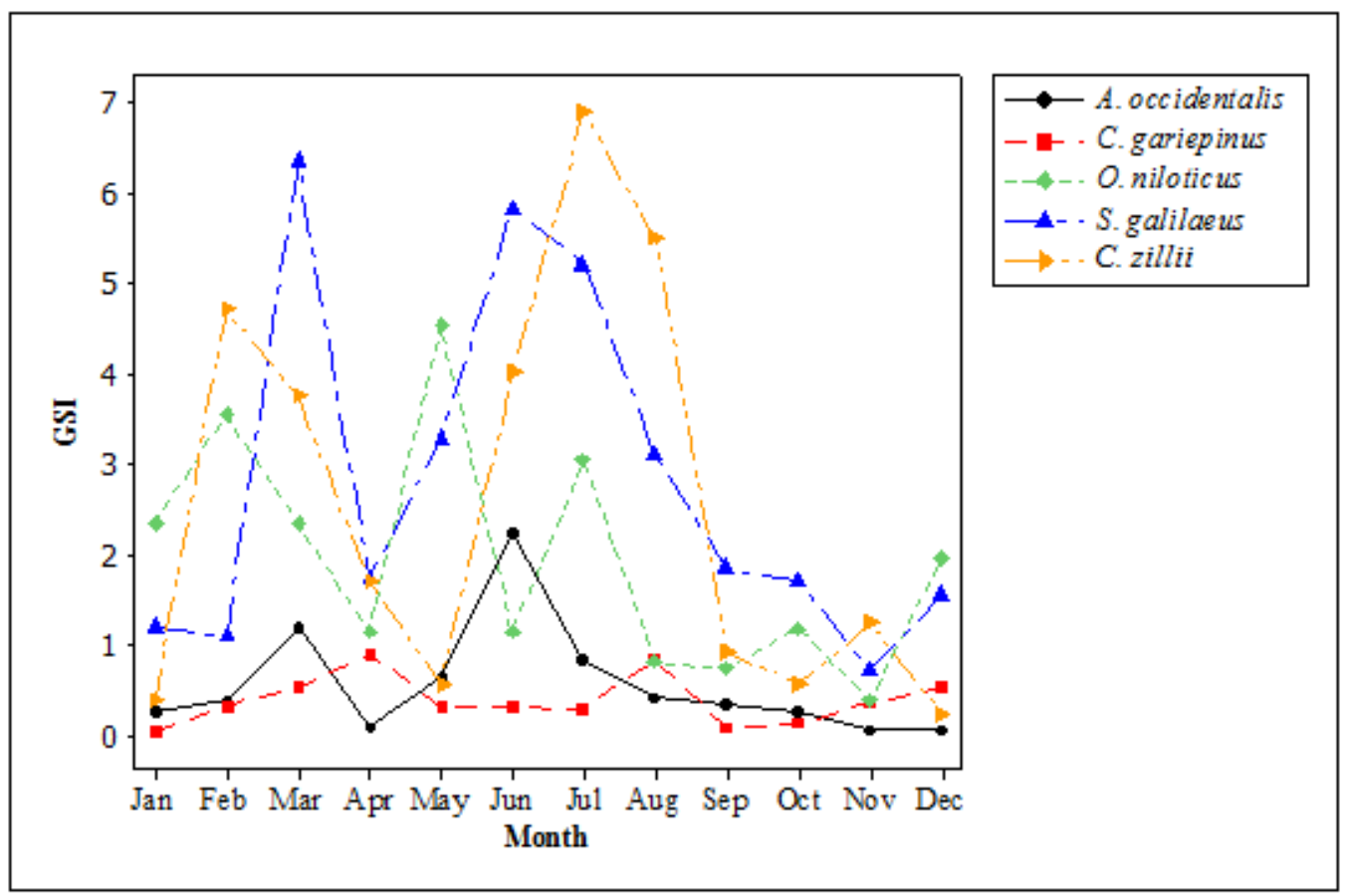

Figure 2. Monthly variation of gonadosomatic indices for females of five major fish species of the Tono Reservoir, Ghana in 2015 and 2016

Table 5 depicts the relationship between fecundity and independent variables namely standard length, fish weight and gonad weight of female specimens of $C$. gariepinus and A. occidentalis. The relationship between fecundity versus standard length, fish weight and gonad weight of female specimens determined by multiple linear regression was significant $(p<0.05)$ for both $C$. gariepinus and $A$. occidentalis. About $96.1 \%$ variation of fecundity was explained by the predictors (standard length, fish weight and gonad weight) for C. gariepinus whilst $89.3 \%$ variation of fecundity was explained by the predictors for $A$. occidentalis. However, these same variables were poor predictors for $C$. galilaeus, $O$. niloticus and $C$. zillii with an R-square of $0.00 \%$ and were excluded. 
Table 5. Relationship between fecundity, standard length, fish weight and gonad weight of female specimens of C. gariepinus and A. occidentalis in the Tono Reservoir, Ghana in 2015 - 2016

\begin{tabular}{|c|c|c|c|c|c|c|c|}
\hline \multicolumn{8}{|c|}{ C. gariepinus } \\
\hline Predictor & $\begin{array}{c}\text { Estimated } \\
\text { Coefficient }\end{array}$ & $\begin{array}{c}\text { SE } \\
\text { Coefficient }\end{array}$ & $\underset{\text { statistic }}{\text { T- }}$ & $p$-value & R-Sq & $\begin{array}{l}\text { R-Sq } \\
\text { (adj) }\end{array}$ & $\begin{array}{l}\text { R-Sq } \\
\text { (pred) }\end{array}$ \\
\hline Constant & -3296.30 & 464.0 & -7.10 & 0.000 & $\begin{array}{l}96.1 \\
(\%)\end{array}$ & $\begin{array}{l}94.6 \\
(\%)\end{array}$ & $87.3(\%)$ \\
\hline $\begin{array}{c}\text { Standard } \\
\text { length }(\mathrm{cm})\end{array}$ & 178.71 & 29.27 & 6.10 & 0.000 & & & \\
\hline Fish weight (g) & 0.97 & 2.32 & 0.42 & 0.687 & & & \\
\hline $\begin{array}{l}\text { Gonad weight } \\
\text { (g) }\end{array}$ & 15.0 & 116.4 & 0.13 & 0.901 & & & \\
\hline \multicolumn{8}{|c|}{ A. occidentalis } \\
\hline Constant & -419.90 & 233.70 & -1.80 & 0.110 & $\begin{array}{l}89.3 \\
(\%)\end{array}$ & $\begin{array}{l}85.3 \\
(\%)\end{array}$ & $\begin{array}{c}76.73 \\
(\%)\end{array}$ \\
\hline $\begin{array}{c}\text { Standard } \\
\text { length }(\mathrm{cm})\end{array}$ & 58.52 & 13.09 & 4.47 & 0.002 & & & \\
\hline Fish weight (g) & -1.53 & 0.27 & -5.76 & 0.000 & & & \\
\hline $\begin{array}{l}\text { Gonad weight } \\
\text { (g) }\end{array}$ & 183.09 & 40.23 & 4.55 & 0.002 & & & \\
\hline
\end{tabular}

\section{Discussion}

\section{Food and feeding habit}

The food composition of the five fish species in the Tono Reservoir was indicative of a high food richness as the specimens exhibited high trophic flexibility by the broad spectrum of food items consumed. The food of the fish species varied from microscopic substances such as plankton to macroscopic items such as macrophytes and animal derivatives. Food items consumed by $A$. occidentalis and C. gariepinus were similar but differed from that of the cichlids. Plankton was noted as the major food of the cichlids but they also had a strong tendency towards plant parts and animal derivative making them omnivores. The results were similar with that of [27] in Nigeria and [28] in Abu-Zabal Lakes, Egypt but contradicted that of [29] who classified them as planktivores. The high trophic plasticity exhibited by cichlids in the current study explains well their survival and resilience despite the sustained fishing pressure on the reservoir. Auchenoglanis occidentalis consumed mainly detritus/sand, plant parts and animal derivatives; an indication of benthic omnivore and agreed with the work done in Lake Akata, Nigeria by [30]. Similarly, the food of $C$. gariepinus was not much different from $A$. occidentalis making it an omnivorous scavenger. This result corroborated with the results of [29].

The diet preference of the fish species except $S$. galilaeus did not vary significantly with seasons attributable to the lack of any considerable seasonal food inputs into the reservoir. The results for $S$. galilaeus contradicted that of [31] who observed no seasonal variation of diet in Lake Bosumtwi, Ghana. S. galilaeus was noted to spawn continuously in the wet season beginning from May to September and this could have accounted for the seasonal variation of food consumed.

\section{Reproductive characteristics}

The results indicated the dominance of males over females. The reason for the male dominance could be that males move away from areas of spawning to where they are captured once fertilization of eggs is established while the females probably go towards submerged vegetation and other areas around the reservoir to evade predators and also continue brooding and protection of the offspring. Related results were observed by [32] for two dominant fish species in Ado reservoir, Southwest Nigeria. The peaks which were observed in GSI indicated that the fish species spawned at least once 
in a breeding season. This agreed with [33], who stated that $O$. niloticus breeds more than once in a season. Furthermore, the GSI of the fish species revealed seasonal variations indicating different spawning intensities for different seasons. The lowest GSI in general was obtained during the dry months (November-April), which constituted the low water level period. Conversely, the peaks happened during the rainy months (May - October), which formed the inundation period conforming to the peaks of the recruitment patterns of the species. This result corroborated with that of [34] for the Bontanga reservoir.

The difference in fecundity noted in this current study is typical in fish [35] and the number of eggs produced by an individual female is influenced by the size, age, health status, availability of food and space [36]. The effect of standard length, fish and gonad weight on fecundity was significant $(\mathrm{p}<0.05)$ for both $C$. gariepinus and A. occidentalis. The regression results showed that the variations of fecundity of $C$. gariepinus $(96.1 \%)$ and A. occidentalis $(89.3 \%)$ were largely explained by standard length, fish and gonad weight leaving the remaining $3.9 \%$ and $10.7 \%$ variation respectively to extraneous parameters not specified in the regression model.

\section{Conclusions}

The food and feeding habits indicated that all five fish species were omnivores. Cyanophyta (Blue-green algae) were noted to be the most important food item for the five fish species. All the five fish species spawned more than once in a year, suggesting their dominance in the reservoir. This study also showed that standard length, fish and gonad weight affect the number of eggs produced per spawning of $C$. gariepinus and A. occidentalis.

\section{Conflict of Interest}

There is no conflict of interest regarding this article.

\section{Acknowledgements}

This study forms part of the author's PhD research work. Sincere appreciation to the laboratory staff of CSIR-Water Research Institute, Tamale for their technical assistance. A profound gratitude to Geoffrey Atigah at Navrongo for constructing gillnets and for supporting in the data collection.

\section{References}

[1] R. Froese, M.L.D. Palomares, D. Pauly, Estimation of life-history key facts. http://www.fishbase.us. 12 June, 2017.

[2] J.L.C Novaes, E.D. Carvalho, Reproduction, food dynamics and exploitation level of Oreochromis niloticus (perciformes: cichlidae) from artisanal fisheries in Barra Bonita reservoir, Brazil. Revista de Biologia Tropical. 60(2) (2012) 721-734.

[3] O. Soyinka, Aspects of the biology and culture trials of cichlids from Lagos lagoon, Journal of Scientific Research and Development. 14(1) (2014).

[4] FAO. The state of world fisheries and aquaculture 2016. Food and Agriculture Organization of the United Nations, Italy. (2016).

[5] H. S. Al-Masroori, S. Bose, Fisheries sustainability and sustainable development, Journal of Fisheries and Aquatic Science. 6 (2011) 1-21.

[6] M. King, Fisheries biology, assessment and management. Fishing News Books, Blackwell Science Ltd, Oxford, 1995.

[7] S.D. Gerking, Feeding ecology of fish. Academic Press, United Kingdom, 1994. 
[8] G. Kraus, J. Tomkiewicz, F.W. Koster. Egg production of Baltic cod (Gadus morhua) in relation to variable sex ratio, maturity and fecundity, Canadian Journal of Fisheries and Aquatic Science. 59 (2002) 1908-1920.

[9] E.H. Alhassan, M. Ansu-Darko, Food and Feeding habits of a potential aquaculture candidate, the black Nile catfish, Bagrus Bajad in the Golinga Reservoir, Australian Journal of Basic and Applied Sciences. 5(5) (2011) 354-359.

[10] E.H. Alhassan, A. Commey, T.B. Bayorbor, An Investigation into the food and feeding habits of Sarotherodon galilaeus (Pisces: Cichlidae) in a shallow tropical reservoir, Research Journal of Fisheries and Hydrobiology. 6(2) (2011) 74-77.

[11] E.D. Abarike, A. Ampofo-Yeboah, Reproductive potential of Nile tilapia (Oreochromis niloticus Linnaeus, 1757) in the Golinga reservoir in Ghana, International Journal of Fisheries and Aquatic Studies. 4(5) (2016) 279-283.

[12] K.K. Mireku, J. Blay, K. Yankson, Reproductive biology of Blackchin tilapia, Sarotherodon melanotheron (Pisces: Cichlidae) from Brimsu Reservoir, Cape Coast, Ghana, International Journal of Fisheries and Aquaculture. 8(4) (2016) 42-54.

[13] C.B. García, C.C. Contreras, Trophic levels of fish species of commercial importance in the Colombian Caribbean, Revista de Biologia Tropical. 59(3) (2011) 1195-203.

[14] S.K. Agodzo, E. Obuobie, C.A. Braimah, The effects of irrigation dams on water supply in Ghana. IOSR Journal of Engineering. 4(5) (2014) 48-53.

[15] S. Adams et al., Water requirements of some selected crops in Tono irrigation area, Journal of Biodiversity and Environmental Science. 4 (2014) 246-257.

[16] D.N. Akongyuure et al., Tono Reservoir fishery contribution to poverty reduction among fishers in northern Ghana, African Journal of Aquatic Science. 42(2) (2017) 143-154.

[17] Ghana Statistical Service. Population and housing census. District Analytical Report, Accra, Ghana, 2014.

[18] R.J. Shiel. A guide to identification of rotifers, rotifers, cladocerans and copepods from Australian waters. Cooperative Research Centre for Freshwater Ecology. Albury, Australia, 1995.

[19] E.G. Bellinger, D.C. Sigee, Freshwater algae: identification, enumeration and use as bioindicators (2nd edn.), Wiley-Blackwell, 2015.

[20] T.B. Bagenal, E. Braum, Eggs and early life history, in: W.E. Ricker, (Ed.). Methods for assessment of fish production in fresh waters. Blackwell Scientific Publications, Oxford, 1968.

[21] T.B. Bagenal, Fecundity. in: B.A. Shinkafi, J.K. Ipinjolu, Gonadosomatic index, fecundity and egg size of Auchenoglanis occidentalis (Cuvier and Valenciennes) in River Rima, NorthWestern Nigeria, Nigerian Journal of Basic and Applied Science. 20(3) (1978) 217-224.

[22] E.J. Hyslop, Stomach contents analysis: A review of methods and their application, Journal of Fish Biology. 17 (1980) 411-429.

[23] A.A. Ugwumba, O.A Ugwumba, Food and feeding ecology of fishes in Nigeria, Crystal Publishers, Lagos, Nigeria, 2007.

[24] M.A. Clark, The food and feeding of seven fish species from the Campbell Plateau, New Zealand, New Zealand Journal of Marine and Freshwater Research. 19 (3) (1985) 339-363.

[25] H. Murua et al., Procedures to estimate fecundity of marine fish species in relation to their reproductive strategy, Journal of Northwest Atlantic Fishery Science. 33 (2003) 33-54. 
[26] E.A. Khallaf, M.M.N. Authman, Some biological aspects of the Nile mormyrid fish (Mormyrus kannume, Forsskal, 1775), from Bahr Shebeen Nilotic Canal, Egypt, World Journal of Fisheries and Marine Sciences. 2 (2010) 357-375.

[27] L.A. Agbabiaka, Food and feeding habits of Tilapia zillii (Pisces: Cichlidae) in river Otamiri South-Eastern Nigeria. Bioscience Discovery. 3(2) (2012) 146-148.

[28] Shalloof KA, Khalifa N, Stomach contents and feeding habits of Oreochromis niloticus (L.) from Abu-Zabal Lakes, Egypt, World Applied Sciences Journal. 6(1) (2009) 1-5.

[29] H.R. Dankwa, E.K. Abban, G.G. Teugels, Freshwater fishes of Ghana: identification, distribution, ecological and economic status. Annales Science Zoologiques. 283 (1999) 53.

[30] O.A. Ikongbeh, F.G. Ogbe, S.G. Solomon, Food and feeding habits of Auchenoglanis occidentalis (Valenciennes, 1775) from Lake Akata, Benue State, Nigeria. Journal of Fisheries and Aquatic Science. 9(4) (2014) 229-236.

[31] S. Amisah, N.W. Agbo, An investigation into the food and feeding ecology of a potential aquaculture candidate, Sarotherodon galilaeus multifasciatus in a meteoritic crater lake in Ghana, Journal of Applied Science and Environmental Management. 12(3) (2008) 15-18.

[32] J.A. Oso et al., Fecundity of two dominant fish species in Ado reservoir, Southwest Nigeria. Albanian Journal Agricultural Science. 12(4) (2013) 603-607.

[33] J.L. Gómez-Márquez, Reproductive aspects of Oreochromis niloticus (perciformes) in Coatetelco Lake, Morelos Mexico, Revista de Biologia Tropical. 51 (2003) 221-228.

[34] K. Kwarfo-Apegyah, P.K. Ofori-Danson, Spawning and recruitment patterns of major fish species in Bontanga Reservoir, Ghana, West Africa, Lakes and Reservoirs: Research and Management. 15 (2010) 3-14.

[35] S. Doha, M.A. Hye, Fecundity of Padma River Hilsa (H. ilisha), Pakistan Journal of Science. 22 (1970) 176-184.

[36] K.F. Lagler, J.F.Z Bardach, R.R. Miller, Ichthyology, John Wiley and Sons, Inc, New York, London, Sydney, 1967. 